\title{
Sober second thought on Canadian health care
}

$\mathrm{M}$ any penetrating ironies flourish in the current Senate scandal, but perhaps the most acute absurdity is the discussion about continuing supplemental medical benefits for recently suspended senators.

Under the Senate's watch, the federal government has largely disengaged from health-policy and health-system planning, causing waste, worry and confusion as provinces and territories struggle to independently monitor and evaluate current performance and identify and support best practice.

At the same time, the health of Aboriginal Canadians - whose health care is the constitutional responsibility of the federal government - remains at substantially lower levels than the health of non-Aboriginal Canadians. With a distressing lack of attention and effective action, the Senate presides over striking and persistent inequities in maternal and child health outcomes, mental health care and communicable disease management.

Moreover, the Senate failed to speak out during the Interim Federal Health Program (IFHP) reform process. Changes to the IFHP substantially reduced health care access and benefits for refugees, one of the most vulnerable populations in the country.

Recently, however, the Senate has finally chosen to engage in the health care debate. Curiously, the motivating issue is not federal health system leadership, Aboriginal health or care for Canada's weak and exposed.

In the setting of historic, controversial and high-profile suspensions, Senate leaders announced that the three suspended members of the upper chamber should continue to receive supplementary medical benefits, echoing the suspended senators themselves, claiming that they will be vulnerable to illness without private health insurance.

Providing supplementary medical benefits to distinguished public servants seems reasonable, and insisting that senators continue to receive benefits, despite suspensions related to accusa-

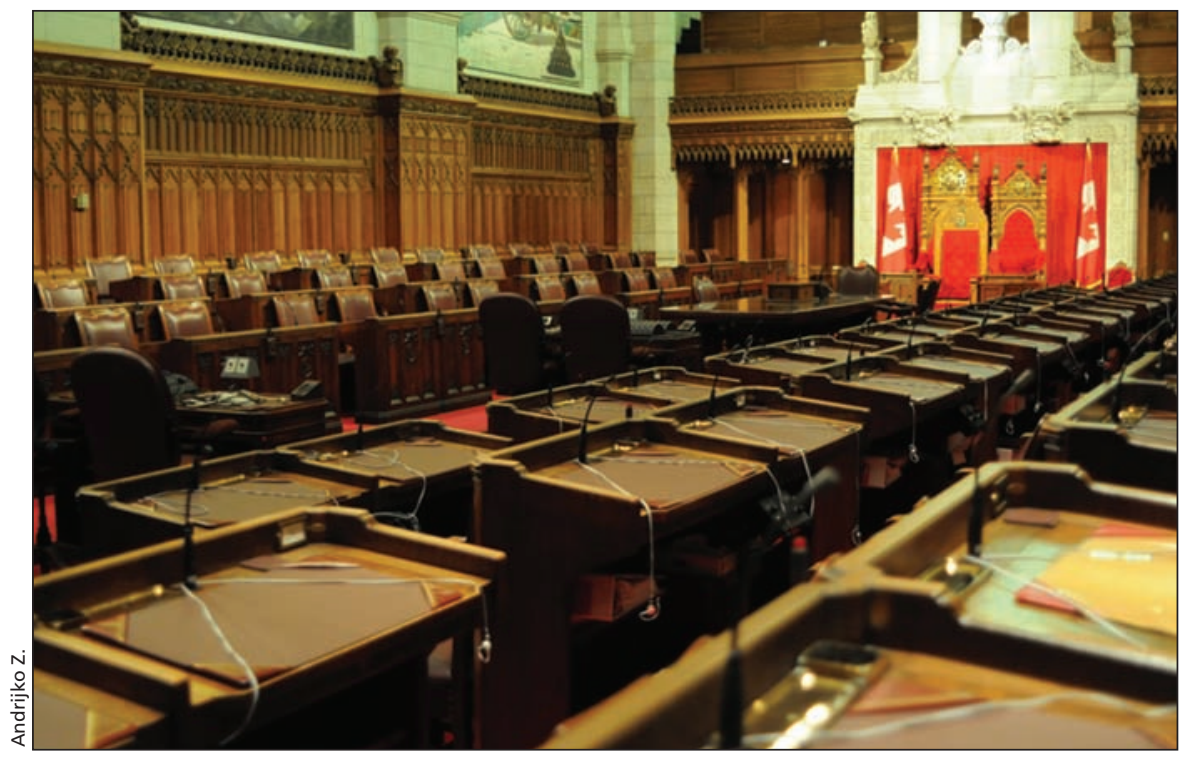

tions of recklessness with public monies, is certainly compassionate. However, it begs many questions: If senators "need" benefits above and beyond those provided to all Canadians, what systemic shortcomings exist in our public health care system? If senators with pre-existing health conditions are considered "vulnerable" and in need of supplemental medical benefits, are all Canadians with (or at risk of) substantial illness equally "vulnerable"? What is the Senate saying about the state of the Canadian health care system?

Parliamentarians are eligible for extended health care benefits through the Public Service Health Care Plan, which covers drugs, vision care, dental care, durable medical equipment, and professional services (including physiotherapy, psychology and massage).

Although sources are inconsistent, it is estimated that one-quarter of our citizens do not have supplemental health benefits. That percentage increases dramatically among those over 65 . Although Canadian seniors should have access to some form of universal pharmaceutical coverage, data from the Organisation for Economic Co-operation and Development show that over $30 \%$ of national health care costs are not publicly funded, including costs related to assistive devices (e.g., eyeglasses, hearing aids and walkers), oral care and allied health services. Out-of-pocket expenditure on health care is about $\$ 700$ per household per capita and both demand for and costs associated with private health care have been steadily increasing over time.

The suspended senators may have a uniquely dysfunctional sense of entitlement, but it is clear that the entire Senate is removed from the reality of the average Canadian. "Reasonable access" to "medically necessary" physician services is an articulated right, according to the Canada Health Act. If this guarantee is insufficient for senators, is it not insufficient for others as well?

The "chamber of sober second thought" ought to use this historic moment to consider its role in securing the foundations of our public health care system, in supporting health system sustainability and in ensuring equitable health outcomes for all Canadians.

\section{Charlotte Moore Hepburn MD \\ Department of Paediatric Medicine \\ Hospital for Sick Children \\ Toronto, Ont.}

CMAJ 2014. DOI:10.1503/cmaj.131787

All editorial matter in CMAJ represents the opinions of the authors and not necessarily those of the Canadian Medical Association. 